\section{INTRINSIC PARAMETERS OF DRY CHOPPED MISCANTHUS FOR COLD PARTICLE DYNAMIC MODELING}

\author{
Pasymia*, Yogi Wibisono Budhib, Yazid Bindarb \\ aDepartment of Chemical Engineering, Faculty of Industrial \\ Technology, Bung Hatta University, Padang, Indonesia \\ bDepartment of Chemical, Food, Bioenergy and Chemurgy \\ Engineerings, Faculty of Industrial Technology, Institut Teknologi \\ Bandung, Indonesia
}

Article history

Received

18 January 2019

Received in revised form

16 July 2020

Accepted

21 July 2020

Published online

27 August 2020

*Corresponding Author pasymi@bunghatta.ac.id

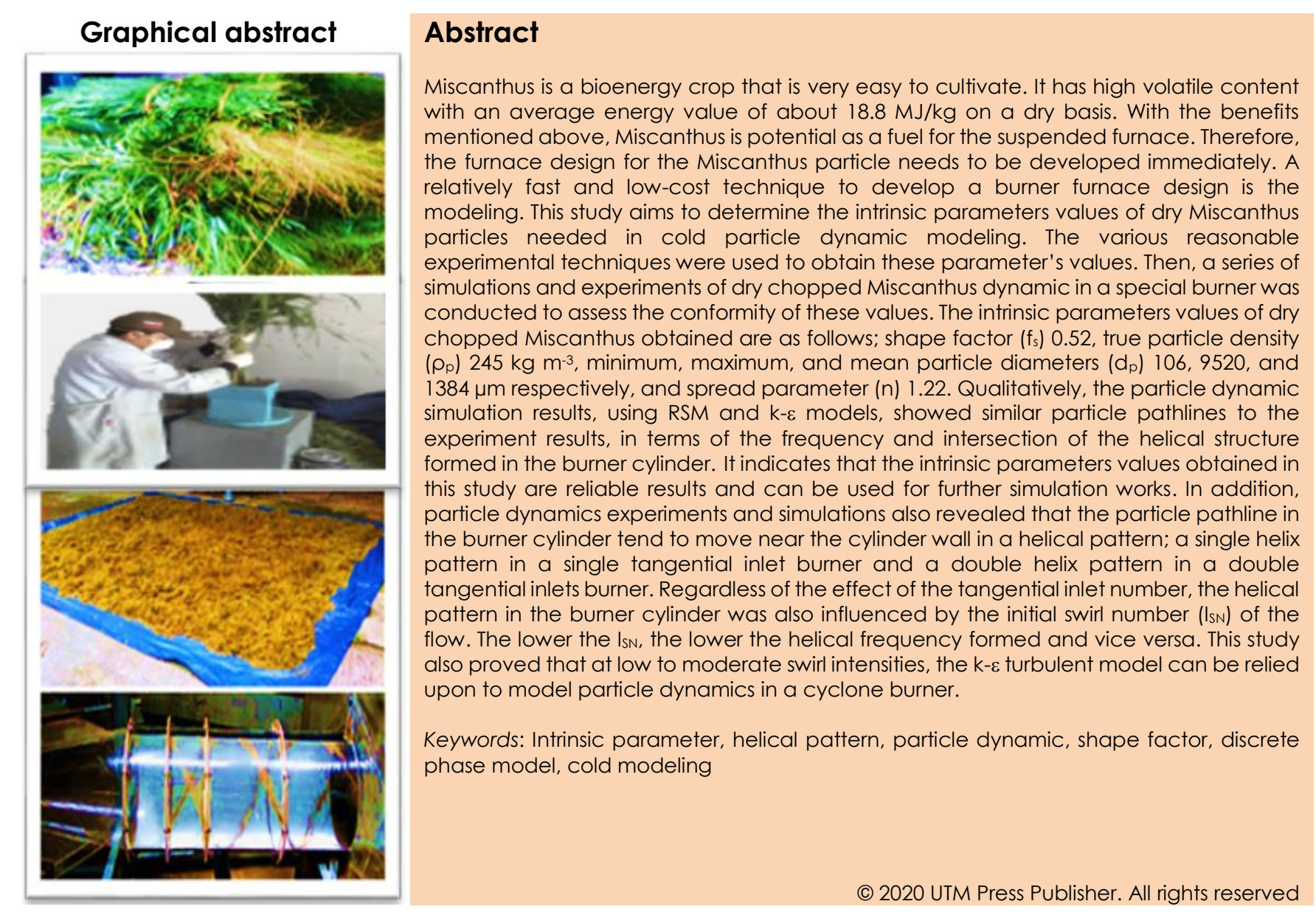

\subsection{INTRODUCTION}

As a consequence of fossil fuels scarcity, the use of biomass as an alternative energy for power plants has increased. Different types of biomass ranging from wood biomass, non-wood biomass, waste biomass and cultivated biomass, have been initiated to be used as primary energy for steam power plants. 
Miscanthus is one of potential bioenergy crops. This particular perennial crop can grow each year and survive for at least fifteen years. In Asia, the average yield of this crop reaches $20+$ dry matter/ha/yr, while in Europe its yield potential could reach $38 t$ dry matter/ha/yr [1]. Miscanthus energy content is reported between 17.8 - $19.8 \mathrm{MJ} / \mathrm{kg}$ (dry basis) [2, 3]. Furthermore, this crop is easily cultivated; it does not require intensive irrigation, fertilization, and pesticide.

With the benefits mentioned above, it is clear that Miscanthus has the potential to be the future energy source for power plants. Therefore, boiler furnace technology using Miscanthus as the energy source needs to be developed. The most suitable boiler furnace technology for steam power plants is the suspended furnace. The combustion process in this type of boiler furnace is easily controlled and has higher thermal efficiency compared to the fixed-bed furnace or fluidized-bed furnace $[4,5]$.

The main problem in designing suspended furnaces is how the particles can be burned completely in a stable suspended condition. This usually happens when the drag time is long or the size of the furnace is large. On the other hand, the furnace design must be kept as small as possible to save investment. So the challenge of designing a suspended furnace is how to condition the particle drag time to be larger but in a small furnace volume. One of the strategies is to involve the swirl flow. For the same furnace volume, swirl flow will tend to produce a longer drag time in the furnace than straight flow.

The technological development core of the suspended furnace lies in the burner design. The burner design is unique; different types of biomass will lead to different geometry and operational conditions. Consequently, although several biomass burners have been previously developed, such as; wood dust (McConnel 48) burner by Kop and Malte, wood powder (VTS) burner by Paulrud and Nilsson, and bagasse swirl burner by Arnao, et al. [6, 7, 8], those designs cannot directly be applied to Miscanthus particles.

Miscanthus burner design needs to be specifically developed based on its particle dynamic and combustion characteristics. The Computational Fluid Dynamics (CFD) method often be used to develop reliable burner designs. It is because the method is proactive, works fast and does not require too much cost [9]. However, the development of burner design through modeling processes requires several parameter values of the fuel particle. Some of these parameters values can be found in the literature but others should be obtained through their own experiment.

This study aims to determine the intrinsic parameter's values of dry chopped Miscanthus, namely; density, shape factor, and particle diameter. The intrinsic parameters have very specific values. The different the anatomy, shape, and size of the particle, as well as the cutting machines, the different the values of these parameters will be [3].
The Miscanthus plants particles used in this study came from the Cibeunying Kidul Region, Bandung, and were chopped with a self-designed cutting machine, so they would have specific characteristics which are not yet available in the literature. This is the main novelty of this research. These parameters are needed to simulate the behavior of cold particle dynamics and have a valuable contribution to the development of Miscanthus burner design (i.e in determining the particle injection strategy).

The successful biomass burner design will serve as a gate for the application and commercialization of biomass steam power plants in the future. This could become a promising solution to the fulfillment of electricity requirements for small islands and remote areas.

\subsection{METHODOLOGY}

The intrinsic parameter's values of the dry chopped Miscanthus were determined through the reasonable experimental techniques. Then, a series of simulations and experiments of dry chopped Miscanthus dynamic, in a special swirl burner, was conducted to assess the conformity of these values. Because of equipment limitation, the results of modeling and experiment can only be compared qualitatively, that is from the pattern of particle trajectories formed in the burner cylinder.

The models used as a qualifier were the RANSbased turbulent models, namely RSM and $k-\varepsilon$, under the Ansys-Fluent software. The model and software have been recognized by many researchers to be able to predict particle dynamics well, especially in cold and isothermal conditions $[6,7,8]$. With the assumption above, if the value of intrinsic parameters used are correct, the experiment and modeling of particle dynamics will be believed to give similar results. If there are deviations the modeling results from the experimental results, the source of the error that should be suspected is the intrinsic parameters.

\subsection{Determination of Intrinsic Parameters}

The intrinsic parameters of biomass particles, such as mean diameter, shape factor, and density, are very specific and complicated. The differences in the type of biomass anatomy, cutting machine, and cutting size will lead to the differences in the intrinsic parameters values. Unfortunately, in the modeling technique, the intrinsic parameters values of the particles are always involved in developing and optimizing the designs and the operating conditions.

The reality above provides a challenge for the researchers to get their own trusted intrinsic parameter values, for the particles they model. This study introduces several reasonable techniques to get reliable intrinsic parameter values, using widely available instruments. 
Particles used in this intrinsic parameter determination were taken from the chopping results of fresh Miscanthus plants using the cutting mill (CM-01). This plant originated from the Cibeunying-Kidul Region, one of the hill areas in Bandung, Indonesia. The plants were harvested at \pm 3 months of age and its height was ranging between $2.0-2.5 \mathrm{~m}$, as depicted in Figure 1 (a).

The cutting mill (CM-01) consists of 5 main parts, those are a feeder, cutting knife, motor, cutting table, and outlet, as shown in Figure 1 (b). The feeder was designed specifically so that the position of the feed and cutting knife was perpendicular to each other. Cutting table plate was installed $10 \mathrm{~mm}$ under the cutting knife. The purpose of this design was to avoid the feed from getting through the product container before being chopped and to get a maximum 10 $\mathrm{mm}$-size product. However, chopped Miscanthus size was influenced by cutting knife sharpness and motor rpm [3]. This cutting knife is driven by a $2 \mathrm{Hp}$ motor with rpm of 1500 .

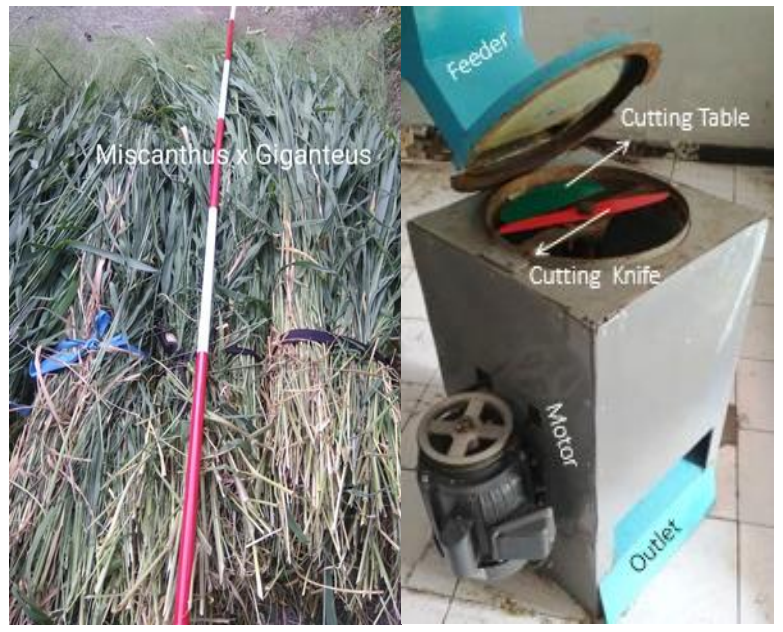

(a) Miscanthus plants

(b) Cutting mill CM-01

Figure 1 Miscanthus plants and cutting mill (CM-01)

\subsubsection{Particle Density}

In this study, there were 2 types of particle density to be determined, namely bulk and true particle densities. Basically, particle density is calculated based on Equation (1).

$$
\rho=m / v
$$

Where:

$\rho=$ particle density

$\mathrm{m}=$ particle mass

$\checkmark=$ particle or bed volume

\section{Bulk Density}

The determination of bulk density $\left(\rho_{b}\right)$ in this study referred to ASAE Standard (American Society of
Agricultural Engineers). The procedure was as follows; (i) pour Miscanthus particles into a $500-\mathrm{ml}$ modified beaker glass; it started $\pm 20 \mathrm{~cm}$ from the beaker glass bottom until the particles overflow, (ii) level out the overflow particles with the surface of the beaker glass, (iii) weigh particle mass in the beaker glass with the accuracy of $0.1 \mathrm{mg}$ and (iv) calculate the bulk density $\left(\rho_{b}\right)$ by dividing particle mass in the beaker glass with the beaker glass volume [10]. The bulk density determination was repeated 10 times.

True Density

In the true particle density $\left(\rho_{t}\right)$ determination, particle mass used in Equation (1) was solid mass plus liquid mass inside (water content). Meanwhile, particle volume used was the particle solid volume only; pore volume was not included [11]. True particle density is influenced by water content and particle anatomy, therefore true particle density determination must be accompanied by anatomy and particle water content analysis.

On the other hand, true particle density is almost free of particle shape and size influences. As a result, true particle density determination can be represented by any particle as long as it comes from the same anatomy component. To ease the process of volume determination, particle shape in this true particle density determination was directed to common shapes such as cylinders, rectangular or cubes.

True particle density determination procedures were as follows: (i) choose 4 particles from each component of stem, leaf, bunches, and flower, (ii) modify the shape of each particle into cylinder or rectangular shape, (iii) weigh each particle using analytical scale of $0.1 \mathrm{mg}$ accuracy, (iv) determine each particle volume using visual enlargement technique with $\pm 0.05 \mathrm{~mm}$ accuracy, and (v) calculate true density of each stem, leaf, bunches, and flower components. An average true particle density of sample particles $\left(\rho_{t, a}\right)$ was calculated using the Equation (2) below.

$$
\rho_{t, a}=A \rho_{t, s}+B \rho_{t, l}+C \rho_{t, b}+D \rho_{t, f}
$$

Where the subscripts of $a, s, l, b$, and $f$ refer to average, stem, leaf, bunches, and flower. Meanwhile, the variables of $A, B, C$, and $D$ are the mass fraction of stem, leaf, bunches and flower, respectively.

\subsubsection{Shape Factor}

In this study, shape factor $\left(f_{s}\right)$ was calculated based on Equation (3).

$$
f_{s}=\frac{A_{s}}{A_{r}}
$$

Where $A_{s}$ is the surface area of a sphere whose volume is the same with sample particle and $A_{r}$ is the real surface area of the sample particle. Surface area 
and particle volume were calculated based on particle average dimension [12], using visual enlargement technique, with $0.05 \mathrm{~mm}$ accuracy. To reduce shape factor disparity, sample particles were classified into 6 sieve result groups.

Shape factor determination procedures for each sieving result group were as follows: (i) choose 3 dominant particles shape for each sieving result group, (ii) determine the volume and surface area of each particle, (iii) for each particle, calculate sphere surface area whose volume is the same with the particle, and (iv) calculate shape factor for each sieving result group. The average shape factor of sample particle $\left(f_{s, a}\right)$ was obtained from the proportional accumulation of each sieve group shape factor, as given by the Equation (4).

$$
f_{s, a}=\sum_{i=1}^{6} x_{i} f_{s}
$$

Where $x_{i}$ is the mass fraction of each sieving result group.

\subsubsection{Particle Diameter}

Particles diameter of Miscanthus is determined through Rosin Rammler approach. In this research, the sample particles were distributed into 6 sieve sizes. The maximum and minimum diameters of the particle were represented by the largest and smallest sieve sizes, respectively. Meanwhile, the particles average diameter $\left(\overline{d_{p}}\right)$ is determined through Equation (5). The value of $\overline{d_{p}}$ is obtained at $\mathrm{y}_{d}=e^{-1}$ [13].

$$
y_{d}=e^{-\left(d_{p} / \overline{d_{p}}\right)^{n}}
$$

Where $d_{p}$ is a representative particle diameter and $\mathrm{y}_{d}$ is the particle mass fraction which has a diameter greater than $d_{p}$. Meanwhile, $\mathrm{n}$ is the distribution parameter. Its value is determined by the Equation (6).

$$
n=\frac{\ln \left(-\ln Y_{d}\right)}{\ln (d / \bar{d})}
$$

\subsection{Conformity Assessment of Intrinsic Parameter's Values}

To assess the suitability of intrinsic parameters values of Miscanthus, which are obtained using the above techniques, a series of particle dynamics simulations have been carried out on a specified burner. The simulation results were then confirmed with the results of the particle dynamics experiments carried out in a transparent burner. Particle pathlines formed in a burner cylinder are used as indicators to assess the feasibility of the intrinsic parameter values of Miscanthus.

The simulation and experiment of particle dynamics were carried out under cold conditions (without combustion), where the intrinsic parameters values haven't changed during the study. The techniques of simulation and experiment used are given in the following description.

\subsubsection{Simulation Technique}

The simulation of particle dynamics in a cyclone burner was conducted under these stages: (i) burner geometry construction, (ii) meshing process, (iii) boundary area identification, and (iv) numerical computation. The geometry and dimension of the simulated burner is shown in Figure 2. The meshing process generated \pm 1.200 .000 control volumes, which were dominated by a hexagonal shape. The modeling was simulated using a Reynolds Stress Model (RSM) and standard $k-\varepsilon$ turbulent model.

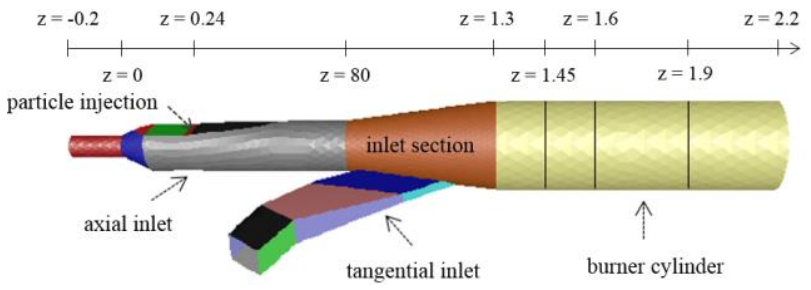

(a) Single tangential inlet burner

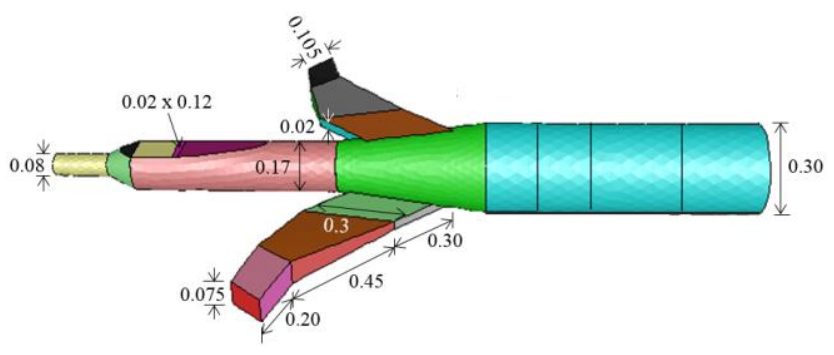

(b) Double tangential inlet burner

Figure 2 The simulated burner geometry (all dimensions in $\mathrm{m}$ )

In discrete phase modeling (DPM), the fluid dynamics is controlled by the Reynold Averaged Navier-Stokes (RANS) equations. Meanwhile, the particle dynamics is governed by the particle momentum conservation law. Generally, the particle momentum conservation equation, for each direction of the cartesian coordinates, is given by the equation below [17].

$$
\frac{\partial \overline{u_{p l}}}{\partial t}=\frac{\overline{u_{\imath}}-\overline{u_{p l}}}{t_{D i}}+\frac{\rho_{p}-\rho}{\rho_{p}} g_{i}+a_{i} ; \text { where } \mathrm{i}=\mathrm{x}, \mathrm{y} \text { and } \mathrm{z}
$$

Variable $\bar{u}_{\imath}$ and $\overline{u_{p}}$ are the average velocities of fluid and particle to the direction of i. Meanwhile, $\rho$ and $\rho_{p}$ are the fluid and particle densities. Variable $t_{D i}$ is the drag time which is the contact time between the particle and the fluid. Variable $g_{i}$ is the gravity toward the direction of $\mathrm{i}$ and $a_{i}$ are other forces that work upon the particles which include: virtual mass force, Saffman's lift force, thermophoretic force, and rocket force.

In this case, the four forces mentioned above were omitted because the modeling was done under cold 
conditions and the particle used has much greater density compared to air. Therefore, Equation (7) can be simplified into,

$$
\frac{\partial \overline{u_{p l}}}{\partial t}=\frac{\overline{u_{\iota}}-\overline{u_{p l}}}{t_{D i}}+\frac{\rho_{p}-\rho}{\rho_{p}} g_{i}
$$

The drag time (t⿰氵) for each direction of a coordinate component is given by Equation (9).

$$
t_{D i}=\frac{\rho_{p} d_{p}^{2}}{18 \mu} \frac{24}{C_{D} N_{R e, i}}
$$

From the above equation, it is shown that particle contact time with air is determined by particle density $\left(\rho_{p}\right)$, particle diameter $\left(d_{p}\right)$, relative Reynold number $\left(N_{R e}\right)$ and drag coefficient $\left(C_{D}\right)$. The value of $C_{D}$ is determined by relative Reynold number $\left(N_{R e}\right)$ and particle shape factor $\left(f_{s}\right)$. For non-spherical particles, the value of $C_{D}$ is formulated by Haider and Levenspiel in Equation (10) and (11).

$$
C_{D}=\frac{24}{R e}\left(1+b_{1} R e^{b_{2}}\right)+\frac{b_{3} R e}{b_{4}+R e}
$$

where:

$$
\begin{aligned}
b_{1}= & \exp \left(2,3288-6,4581 f_{s}+2,4486 f_{s}^{2}\right) \\
b_{2}= & 0,0964+0.5565 f_{s} \\
b_{3}= & \exp \left(4,905-13,8944 f_{s}+18,4222 f_{s}^{2}\right. \\
& \left.-10,2599 f_{s}^{3}\right) \\
b_{4}= & \exp \left(1,4681+12,2584 f_{\mathrm{s}}-20,7322 \mathrm{f}_{\mathrm{s}}{ }^{2}\right. \\
& \left.+15,8855 f_{s}^{3}\right)
\end{aligned}
$$

Variable $f_{s}$ is a shape factor. For a spherical particle, $f_{s}=1$, while for non-spherical particles, $f_{s}<1$. Particle shape factor is determined by Equation (3). Meanwhile, the relative Reynolds number equation is given by the equation below.

$$
N_{R e, i}=\frac{d_{p}\left|\overline{u_{l}}-\overline{u_{p l}}\right| \rho}{\mu}
$$

According to Equation (9), the dynamic (drag time) of a particle is directly proportional to the density and size of the particles and inversely proportional to the particle drag coefficient. The drag coefficient of a particle is a function of particle shape, where the smaller the shape factor value, the greater the drag coefficient value will be and vice versa.

From the explanation above, it has been proven that particle dynamics modeling requires intrinsic parameter values of the modeled particles, namely particle shape $\left(f_{s}\right)$, particle density $\left(\rho_{\mathrm{p}}\right)$, and particle diameter $\left(d_{p}\right)$. Therefore, before particle dynamics modeling is carried out, the values of these parameters must be determined first.

\subsubsection{Experimental Set-Up}

Particle dynamics experiment was conducted in a transparent swirl burner made from acrylic material. The burner outlet is connected to a rectangular box as a furnace imitation. The particle dynamics experiment set-up used in this study is shown in Figure 3.

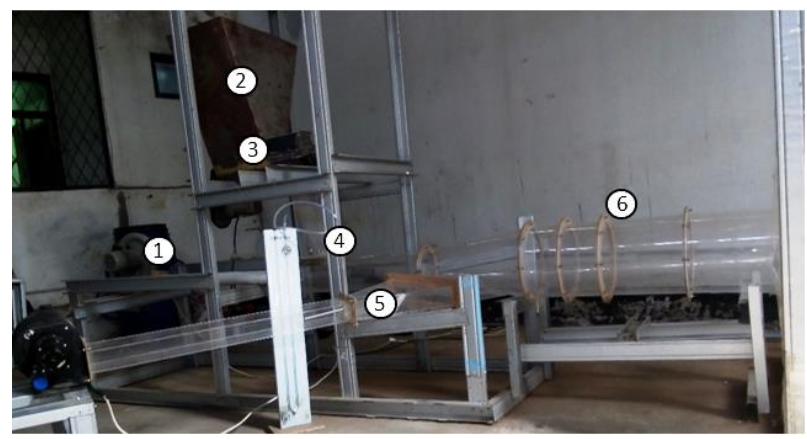

Figure 3 Experimental set-up of fluid dynamics; (1) axial air inlet, (2) bin feeder, (3) screw feeder, (4)particle injection port, (5) tangential air inlet, and (6) cylinder body

The experimental procedures of particle dynamics were as follows: (1) turn on the blower in both inlets, (2) set up the blower opening based on the desired flow rate, (3) turn on the screw feeder and set the motor velocity up according to the desired particle injection rate, (4) observe and visualise particle dynamics in the burner cylinder using a camera.

Airflow rate measurement is done by pitot meter. The experiment was conducted for a variety of tangential inlet numbers and Initial Swirl Number $\left(I_{S N}\right)$. Refer to [15], the Initial Swirl Number $\left(I_{S N}\right)$ is represented by the equation below.

$$
I_{S N}=\left(\dot{m}_{t} / \dot{m}_{T}\right)^{2}\left(A_{T} / A_{t}\right)^{2}
$$

Variables $m$ and $A$ are mass flow rate and surface area, respectively. Meanwhile, the subscript $t$ and $T$ refer to the tangential inlet and burner cylinder. The $I_{S N}$ variation used in this study was in between 12.7-30.4.

Particle injection in the burner is done through a rectangular shaped surface with the surface area of \pm $24 \mathrm{~cm}^{2}$. The injection hole was built in the axial inlet, located $0.24 \mathrm{~m}$ from the burner head. Particle injection rate used was $\pm 0.02 \mathrm{~kg} / \mathrm{s}$.

\subsection{RESULT AND DISCUSSION}

\subsection{The Intrinsic Parameter of Dry Chopped Miscanthus}

Approximately, $80 \%$ of the chopped product of cutting mill (CM-01) could pass through 10-mm size sieve at the first separation. The remainder (over size) is put into the cutting machine again. That particle size has met the particle size specification of biomass for suspended combustion purpose ( $\leq 10 \mathrm{~mm}$ ), as used by some previous researchers $[4,8,17]$.

In terms of shape, chopped dry Miscanthus particles were dominated by the cylinder and the rectangular shapes. Cylinder shape generally came 
from the bunches and stem components. As for rectangular shape, some came from leaf components and others from stem components. This above characteristic is in accordance with what Baxter et al. claimed, that the chopped biomass particle shape is commonly dominated by cylinder and slab shape [18].

\subsubsection{Particle Density}

There are two-particle densities determined here, which are bulk density and true density on average. The average bulk density of dry Miscanthus particles from the measurement was $101.23 \mathrm{~kg} / \mathrm{m}^{3}$. The recapitulation of Miscanthus particle bulk density determination results, in $500 \mathrm{ml}$ modified beaker glass, is given in Table 1. This bulk density value was close to the one reported by Dahl \& Obernberger (2004), which was $117 \mathrm{~kg} / \mathrm{m}^{3}$ [19].

The difference between the bulk density value obtained here and the values in the literature may be caused by the difference in particle size, grinder/cutting mill types, and particle water content. The effect of grinder types upon bulk density has been reported by Victor et al. (2016); particles formed by grinders tend to have bigger bulk density compared to particles formed by cutting mills [3]. The average water content of the dry chopped Miscanthus used in this study is $12.35 \%$.

Table 1 Miscanthus particle bulk density

\begin{tabular}{ccc}
\hline $\begin{array}{c}\text { Sample } \\
\text { Number }\end{array}$ & Weight (gram) & $\begin{array}{c}\text { Density } \\
\left(\mathbf{g r} / \mathbf{d m}^{3}\right)\end{array}$ \\
\hline I & 51.1896 & 102.38 \\
II & 49.0473 & 98.09 \\
III & 50.1567 & 100.31 \\
IV & 50.1567 & 100.31 \\
V & 51.2305 & 102.46 \\
VI & 51.2924 & 102.58 \\
VII & 49.4632 & 98.93 \\
VIII & 50.6683 & 101.34 \\
IX & 51.2252 & 102.45 \\
X & 51.2523 & 102.5 \\
\hline Average Miscanthus bulk density \\
\hline \multicolumn{3}{c}{}
\end{tabular}

In this study, the determination of the true particle density is represented by 16 particles, where each part of the anatomy (stem, leaf, bunches, and flowers) is represented by 4 particles. The true particle density of each component of stem, leaf, bunches, and flower are $279,192,248$, and $237 \mathrm{~kg} / \mathrm{m}^{3}$. The proportion of each anatomy component is subjected to the season, soil condition, and plant harvest age $[3,20]$.

From the anatomical analysis of 10 sample stems, it was revealed that the composition of the Miscanthus plant weight was as follows: $57 \%$ stem component, $36 \%$ leaf component, $4 \%$ bunches component, and $3 \%$ flower component. Then, the average true particle density of the Miscanthus particle, calculated from the Equation (2), is $\pm 245 \mathrm{~kg} / \mathrm{m}^{3}$.

\subsubsection{Shape Factor}

The sieving results of dry Miscanthus particles are shown in Figure 4. All 6 groups of sieving results showed almost uniform shape and size. Then, using Equation (3), the shape factor of some particle representatives from each sieving result group was determined.
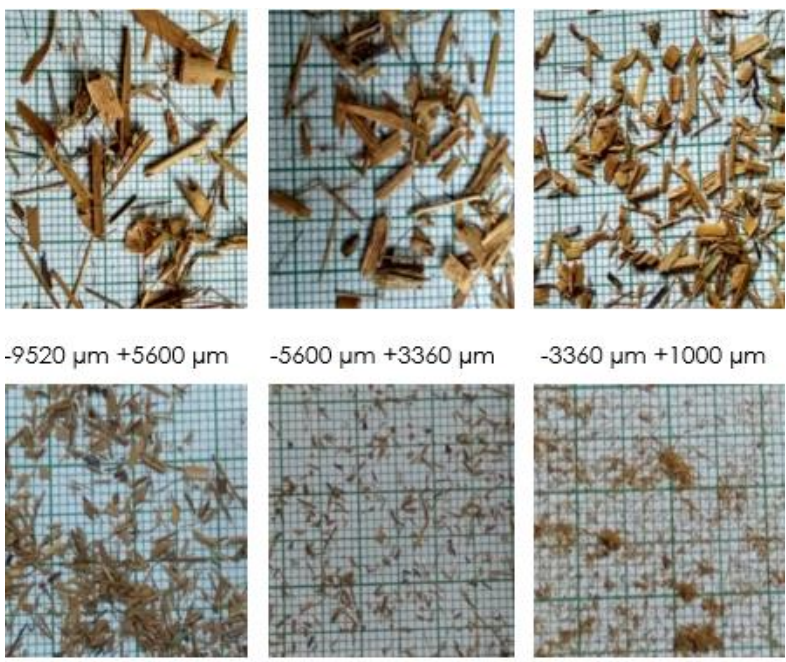

$-1000 \mu m+850 \mu m$

$-850 \mu m+106 \mu m$

$-106 \mu \mathrm{m}$

Figure 4 Miscanthus particles visualization of each sieving result group

The shape factor of each sieving result group $\left(f_{s, i}\right)$ are shown in Table 2. An average shape factor of dry chopped Miscanthus $\left(f_{s, a}\right)$, which is calculated from Equation (4), is 0.52 .

Table 2 Sieve analysis of Miscanthus particles

\begin{tabular}{lccccc}
\hline $\begin{array}{c}\text { Sieving size, } \\
\boldsymbol{\mu m}\end{array}$ & $\boldsymbol{X}_{\mathbf{d}}$ & $\begin{array}{c}\left(\boldsymbol{1}-\sum \boldsymbol{X}_{\mathbf{d}}\right) \\
\text { or } \boldsymbol{Y}_{\boldsymbol{d}}\end{array}$ & $\boldsymbol{f}_{\text {s.i }}$ & $\boldsymbol{f}_{\text {s.a }}$ & $\boldsymbol{n}$ \\
\hline-106 & 0.010 & 0.99 & 0.58 & 0.0058 & 1.79 \\
$-850+106-$ & 0.227 & 0.763 & 0.54 & 0.1226 & 2.68 \\
$-1000+850$ & 0.359 & 0.404 & 0.54 & 0.1939 & 0.30 \\
$-3360+1000$ & 0.221 & 0.183 & 0.52 & 0.1149 & 0.60 \\
$5600+3360$ & 0.121 & 0.062 & 0.50 & 0.0605 & 0.73 \\
$-9530+5600$ & 0.062 & 0 & 0.43 & 0.0267 & 0 \\
\hline & & & & 0.5244 & 1.22 \\
\hline
\end{tabular}

\subsubsection{Average Particle Diameter}

A list of accumulated particle mass fraction $\left(Y_{d}\right)$ and particle distribution parameter (n) for each sieving result group is shown in Table 2. It is clear from this table that the minimum particle diameter is $106 \mu \mathrm{m}$, maximum particle diameter is $9520 \mu \mathrm{m}$, and the average distribution parameter $(n)$ is 1.22. Meanwhile, the average particle diameter $\left(\overline{d_{p}}\right)$, obtained from Figure 5, is $1384 \mu \mathrm{m}$. 


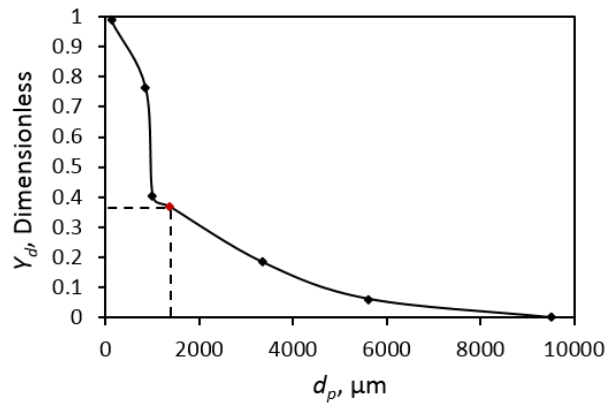

Figure 5 Relationship curve of particle diameter $\left(d_{p}\right)$ and accumulated mass fraction $\left(Y_{d}\right)$

In cold modeling, density, shape factor and diameter of the particle can be considered constant, because the particle is assumed inert during the operation. However, in combustion modeling, this value may change during the combustion process. Rapid water evaporation and volatile substances release will cause rapid particle weight loss and will result in the change of particle shape and size. These changes would also happen during the char combustion stage [21, 22].

\subsection{Experimental and Modeling Results of the Cold Particle Dynamic}

The simulation results, using the RSM and k- $\varepsilon$ turbulent models, have shown a similar particle dynamics to the experimental results, in terms of frequency and intersection of the helical structure in the burner cylinder, as shown in Figures 6 and 7. Due to camera limitation, the experimental particle pathline visualized in this study was only the steady movement by a group of the particle, not by an individual particle.

These results indicated that intrinsic parameters values used in modeling have sufficiently represented dry chopped Miscanthus characteristics. It also means that the experimental techniques used, in determining the intrinsic parameter of Miscanthus particles, are quite effective.

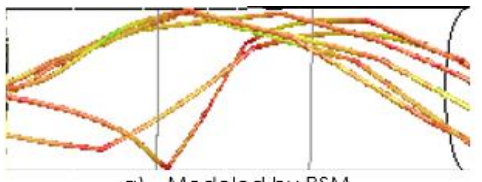

a) Modeled by RSM

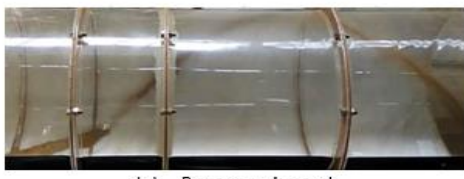

b) By experiment

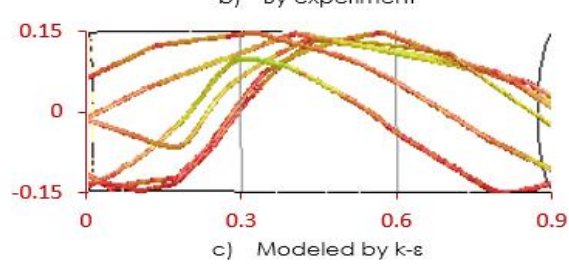

(i) Initial swirl number $\left(I_{s N}\right)=22.3$
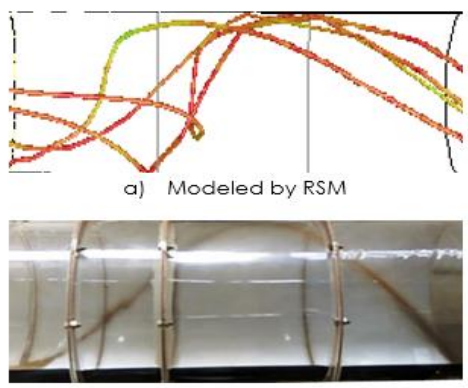

b) By experiment

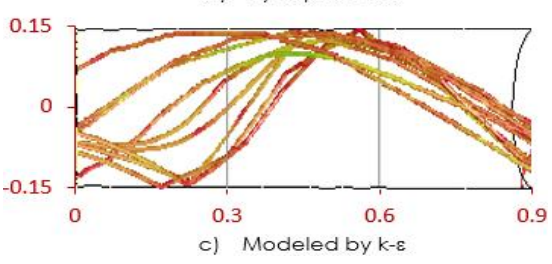

(ii) Initial swirl number $\left(I_{\mathrm{SN}}\right)=28.5$
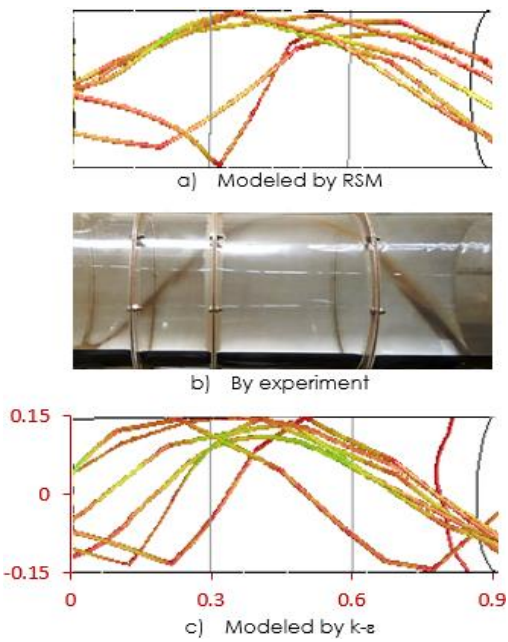

(iii) Initial swirl number $\left(I_{s N}\right)=30.4$

Figure 6 Comparison between experimental and simulation particle pathlines in a cylinder burner at several Iss (with single tangential inlet and tangential inlet thickness $=2 \mathrm{~cm}$ )
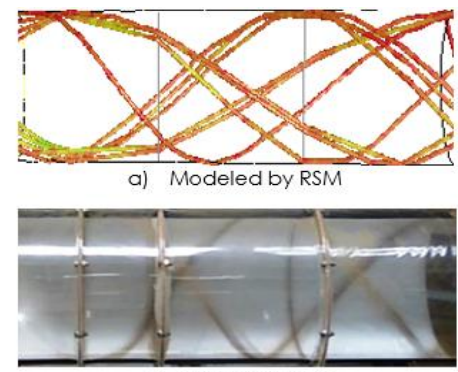

b) By experiment

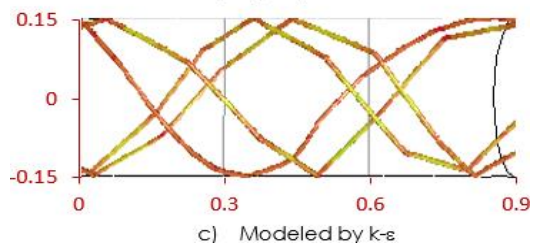

(i) Initial swirl number $\left(I_{S N}\right)=12.7$ 


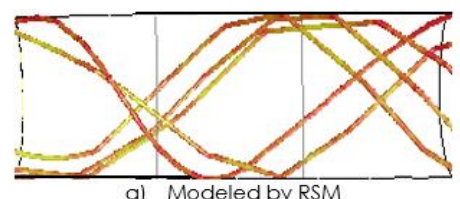

a) Modeled by RSM

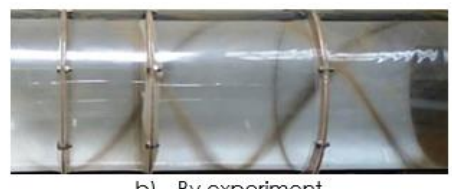

b) By experiment

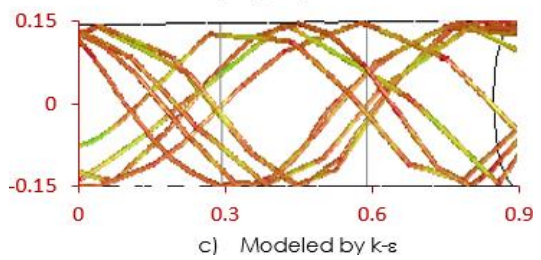

(ii) Initial swirl number $(\operatorname{lsN})=13.3$

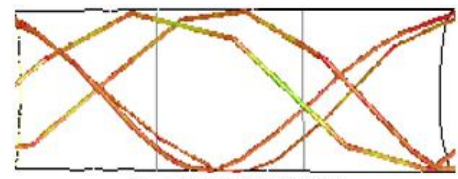

a) Modeled by RSM

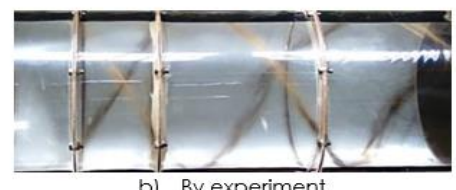

b) By experiment

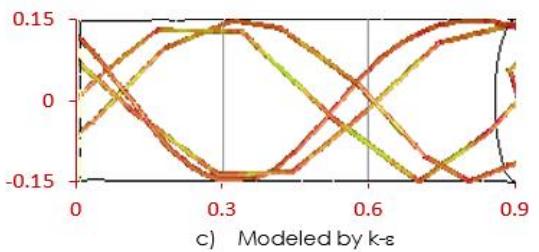

(iii) Initial swirl number $\left(I_{S N}\right)=14.9$

Figure 7 Comparison between experimental and simulation particle pathlines in a cylinder burner at several ISN (with double tangential inlet and tangential inlet thickness $=3 \mathrm{~cm}$ )

Furthermore, fluid dynamics modeling and experimentation also revealed that the particles move near the cylinder wall in a helical pattern. In the burner with a single tangential inlet, the particle trajectory pattern was in the form of a single helix (Figure 6). Meanwhile, in the burner with a double tangential inlet, the particle trajectory pattern was in the form of a double helix (Figure 7).

Besides being influenced by the number of tangential inlets, the helix pattern formed in the burner cylinder is also influenced by the IsN value. For a burner with a single tangential inlet, the influence of ISN was shown from the helix length. Experimental result for ISN 22.3 showed that the helix length was greater than 0.9 $\mathrm{m}$ (Figure 6(a)). Meanwhile for IsN 30.4 and 28.5, the experimental results showed that the helix length was $\leq 0.9 \mathrm{~m}$ (Figure 6(b) and (c)). The lower the Is values, the longer the length of the helix and vice versa. A comparison of the particle dynamic characteristics in a burner with single tangential inlet, between simulation and experimental results, was given in Table 3.

Table 3 Comparison of particle dynamic in a burner cylinder with a single tangential inlet between modeling and experimental results

\begin{tabular}{|c|c|c|c|c|}
\hline$I_{S N}$ & Parameter & RSM & $k-\varepsilon$ & Eksperimen \\
\hline 22.3 & $\begin{array}{l}\text { Helical number } \\
\text { Helical length }\end{array}$ & $\begin{array}{l}\text { Single } \\
>>>0.9\end{array}$ & $\begin{array}{l}\text { Single } \\
>>>0.9\end{array}$ & $\begin{array}{l}\text { Single } \\
>0.9\end{array}$ \\
\hline 28.5 & $\begin{array}{l}\text { Helical number } \\
\text { Helical length }\end{array}$ & $\begin{array}{l}\text { Single } \\
>>0.9\end{array}$ & $\begin{array}{l}\text { Single } \\
>>0.9\end{array}$ & $\begin{array}{l}\text { Single } \\
\geq 0.9\end{array}$ \\
\hline 30.4 & $\begin{array}{l}\text { Helical number } \\
\text { Helical length }\end{array}$ & $\begin{array}{l}\text { Single } \\
\geq 0.9\end{array}$ & $\begin{array}{l}\text { Single } \\
\geq 0.9\end{array}$ & $\begin{array}{l}\text { Single } \\
\leq 0.9\end{array}$ \\
\hline
\end{tabular}

In a burner with a double tangential inlet, each helix had the opposite direction. Therefore, from the $2 \mathrm{D}$ perspective, as if there are some intersections formed between the two helices. The number and positions of the intersections were influenced by ISN values; the lower the IsN, the fewer number of intersections was formed. For $I_{S N} 12.7$ and 13.3, the experimental result showed there are 2 intersections formed in the burner cylinder, located in compartment 2 (C2) and C3 (Figure 7(a) and (b)). Meanwhile, for $I_{S N}=14.9$, the intersection number was still 2, but the intersection positions were located in $\mathrm{Cl}$ and C2 (Figure 7(c)).

In the modeling results, although the number of intersections produced is the same, the position of the intersection is slightly different compared to the experimental results. For ISN 12.7, the intersection position on the RSM model is seen in compartment 2 (C2) and interface 3 (I3). While, on the k- $\varepsilon$ model, the intersection position is seen in $\mathrm{Cl}$ and 12 . A comparison of the particle dynamic characteristics in a burner with double tangential inlets, between simulation and experimental results, can be seen in Table 4.

Table 4 Comparison of particle dynamic in a burner cylinder with a double tangential inlet between modeling and experimental results

\begin{tabular}{|c|c|c|c|c|}
\hline$I_{S N}$ & Parameter & RSM & $\mathrm{k}-\varepsilon$ & Experiment \\
\hline \multirow{3}{*}{12.7} & Helical number & Double & Double & Double \\
\hline & Intersection & 2 & 2 & 2 \\
\hline & Posisition & $C 2 \& 13$ & $C 1 \& 12$ & $C 2 \& C 3$ \\
\hline \multirow{3}{*}{13.3} & Helical number & Double & Double & Double \\
\hline & Intersection & 2 & & \\
\hline & Posisition & $11 \& C 3$ & $\mathrm{Cl} \& 12$ & $C 2 \& C 3$ \\
\hline \multirow{3}{*}{14.9} & Helical number & Double & Double & Double \\
\hline & Intersection & 2 & 2 & 2 \\
\hline & Posisition & $\mathrm{Cl} \& \mathrm{C} 3$ & $C 1 \& C 2$ & $\mathrm{C} 1 \& \mathrm{C} 2$ \\
\hline
\end{tabular}

Although in theory, the ability of the RSM turbulent model is better in predicting the swirl turbulent flow than the standard k- $\varepsilon$ turbulent model, but in reality, under the modeling conditions used, the two models show almost the similar results [25]. Even at a low swirl 
flow intensity, the results given by the $k-\varepsilon$ turbulence model were closer to the experimental results, compared to RSM. The above result was similar to the Vazquez finding, where for a certain $I_{S N}$, the quantitative predictions of the $k-\varepsilon$ turbulent model for predicting axial and tangential velocities in swirl burner were better compared to RSM [26]. Thus, this study also confirms that the k- $\varepsilon$ turbulent model can be used to predict particle dynamics in cyclone burner.

\subsection{CONCLUSION}

The intrinsic parameter values of dry Miscanthus particles, produced by chopping mills (CM-01), have been obtained through several reasonable experimental techniques. Those intrinsic parameters values were then confirmed through modeling using the RANS-based turbulent models (RSM and k- $\varepsilon$ ) under Ansys-Fluent software. It was found that the fluid dynamics pattern i.e the frequency and the intersection of helical structure in burner cylinder, which is generated from modeling are similar to the experimental results. It indicates that the intrinsic parameter values used in modeling are close to the truth and can be used for further simulation works. The intrinsic parameter values of dry chopped Miscanthus obtained are as follows: (i) true particle density 245 $\mathrm{kg} / \mathrm{m} 3$, (ii) shape factor 0.52, (iii) minimum diameter $106 \mu \mathrm{m}$, (iv) maximum diameter $9520 \mu \mathrm{m}$, (v) average diameter $1384 \mu \mathrm{m}$, and distribution parameter 1.22.

Experiment and simulation results also revealed that the particle pathline in the burner cylinder has a helical pattern. A single helical pattern was formed in the burner with a single tangential inlet and a doublehelical patterns were formed in the burner with a double tangential inlet. Apart from the geometry, the helical pattern i.e the frequency and intersection of the helical structure in the burner cylinder were also influenced by the initial swirl number $\left(I_{S N}\right)$ of the flow. The lower the $I_{S N}$, the lower the helical frequency formed and vise versa.

The last results obtained from this study are proof that the $k-\varepsilon$ turbulent model is able to model particle dynamics in a cyclone burner quite well, almost similar to the RSM. Because the $k-\varepsilon$ turbulent model has a smaller computational effort compared to the RSM, then the use of the k-e model will be more interesting.

\section{Acknowledgement}

This study is supported by the Directorate of Research and Community Service, Ministry of Research and Technology, Republic of Indonesia. The funding support, given under the scheme of Ph.D. dissertation research grant, has significantly helped the implementation of this research. Therefore, the authors appreciate it gratefully.

\section{References}

[1] Chung, J. H. and Kim, D. S. 2012. Miscanthus as a Potential Bioenergy Crop in East Asia. Journal of Crop Science and Biotechnology. 15(2): 65-77.

Doi: 10.1007/s12892-012-0023-0.

[2] Vanja, J., Nikola, B., Tajana, K., Josip, L., Ana, M. and Ivan, K. 2014. Fuel Properties' Comparison of Allochthonous Miscanthus $x$ Giganteus and Autochthonous Arundo Donax L.: A Study Case in Croatia. Agriculturae Conspectus Scientificus. 79(1): 7-11.

[3] Victor, T., Andrei, G., Alexandru, U., Mihai, G. and Aurelia, L. 2016. Prospects for the Utilization of the Miscanthus Giganteus and Polygonum Sachalinense for Solid Biofuel Production in the Republic of Moldova. A. Agronomy. 59: 543-546.

[4] Luo, S., Xiao, B., Hu, Z., Liu, S. and He, M. 2010. Experimental Study on Combustion of Biomass Micron Fuel (BMF) in Cyclone Furnace. Energy Conversion and Management. 51: 2098-2102

Doi:10.1016/j.enconman.2010.03.001.

[5] Tokarski, S., Głod, K., Sciazko, M. and Zuwała, J. 2015. Comparative Assessment of the Energy Effects of Biomass Combustion and Co-Firing in Selected Technologies. Energy. 30: 1-9.

Doi:10.1016/j.energy.2015.06.044.

[6] Stephen, M. B. K. and Philip, C. M. 2004. Simulation and Modeling of Wood Dust Combustion in Cyclone Burners. Final Technical Report. U. S. Department of Energy. 1-49.

[7] Susanne, P. and Calle, N. 2004. The Effects of Particle Characteristics on Emissions from Burning Wood Fuel Powder. Fuel. 83: 813-821. Doi:10.1016/j.fuel.2003.10.010.

[8] Juan, H. S. A., Daniel, J. O. F., Caice, G. S., Justo, E. A. Leonardo, P. R. and Song, W. P. 2015. The Influence of Swirl Burner Geometry on the Sugar-Cane Bagasse Injection and Burning. International Journal of Mechanical, Aerospace, Industrial, Mechatronic and Manufacturing Engineering. 9(5): 798-801.

[9] Pragati, K. and Sharma, H.K. 2013. Concept of Computational Fluid Dynamics (CFD) and its Applications in Food Processing Equipment Design. Journal of Food Processing and Technology. 3: 1-7. Doi:10.4172/2157-7110.1000138.

[10] Chevanan, N., Womac, A. R. and Bitra, V. S. 2008. LooseFilled and Tapped Densities of Chopped Switchgrass, Corn Stover and Wheat Straw. ASABE Annual International Meeting. Rhode Island, USA.

[11] Lam, P. S., Sokhansanj, S., Bi, X., Mani, S., Lim, C. J., Womac, A. R., Hoque, M., Peng, J., JayaShankar, T., Naimi, L. J. and Nayaran, S. 2008. Bulk Density of Wet and Dry Wheat Straw and Switchgrass Particles. Applied Engineering in Agriculture. 24(3): 351-358. Doi: $10.13031 / 2013.24490$

[12] Peter, F. D., Jay, G. S., Douglas, R. W., Paul, D. and Jose, L. J. 2004. Particle Morphology and Density Characterization by Combined Mobility and Aerodynamic Diameter Measurements. Part 1: Theory. Aerosol Science and Technology. 38: 1185-1205. Doi: 10.1080/027868290903907.

[13] Carter, R. M. and Yan, Y. 2005. Measurement of Particle Shape Using Digital Imaging Techniques. Journal of Physics: Conference Series. 15: 177-182. Doi:10.1088/1742-6596/15/1/030.

[14] Baxter, L., Ip, L., Lu, H. and Tree, D. 2005. Distinguishing Biomass Combustion Characteristics and Their Implications for Sustainable Energy. The $5^{\text {th }}$ Asia Pacific Conference on Combustion. University of Adelaide, Australia.

[15] Ansys Inc. 2013. Ansys Documentation: Solver Theory.

[16] Chen, J., Haynes, B. S. and Fletcher, D. F. 1999. A Numerical and Experimental Study of Tangentially Injected Swirling Pipe Flows. $2^{\text {nd }}$ International Conference on CFD in the Minerals and Process Industries. Melbourne, Australia. 
[17] Yazid, B. 2017. Computation Engineering on MultiDimensional Turbulent Flows (in the Indonesian Language). First Edition. ITB Press, Bandung, Indonesia.

[18] Lasse, A. R., Chungen, Y., Søren, K. K., Klaus, F. and Peter, O. 2007. Physical Characterization of Biomass Fuels Prepared for Suspension Firing in Utility Boilers for CFD Modelling. Biomass and Bioenergy. 31: 318-325. Doi: 10.1016/j.biombioe.2007.01.015

[19] Jonas, D. and Ingwald, O. 2004. Evaluation of the Combustion Characteristics of Four Perennial Energy Crops (Arundo Donax, Cynara Cardunculus, Miscanthus X Giganteus and Panicum Virgatum). 2nd World Conference on Biomass for Energy, Industry and Climate Protection. Rome. Italy.

[20] Mariusz, J. S., Michal, K., Malwina, S., Emilia, S., Marek, P. and Radoslaw, F. 2014. Thermophysical and Chemical Properties of Perennial Energy Crops Depending on Harvest Period. International Agrophysics. 28: 201-211. Doi: 10.2478/intag-2014-0009.

[21] Momeni, M., Yin, C., Kaer, S. K., Hansen, T. B., Jensen, P. A. and Glarborg, P. 2013. Experimental Study on Effects of Particle Shape and Operating Conditions on Combustion Characteristics of Single Biomass Particles. Energy and Fuels. 27(1): 507-514.
Doi: 10.1021/ef301343q.

[22] Holmgren, P., Wagner, D. R., Strandberg, A., Molinder, R. Wiinikka, H., Umeki, K. and Broström, M. 2017. Size, Shape and Density Changes of Biomass Particles during Rapid Devolatilization. Fuel. 206: 342-351. Doi:10.1016/j.fuel.2017.06.009

[23] Elfasakhany, A., Klason, T. and Bai, X. S. 2008. Modeling of Pulverised Wood Combustion Using a Functional Group Model. Combustion Theory and Modelling. 12(5): 883-890. Doi: 10.1080/13647830802094344.

[24] Chinsung, M., Hookyung, L., Sangmin, C. and Vasilije, $M$. 2016. Combustion Behavior of Relatively Large Pulverized Biomass Particles at Rapid Heating Rates. Energy \& Fuels. 30: 10809-10822. DOI: 10.1021/acs.energyfuels.6b01457.

[25] Escue, A. and Cui, J. 2010. Comparison of Turbulence Models in Simulating Swirling Pipe Flows. Applied Mathematical Modelling. 34: 2840-2849. Doi: 10.1016/j.apm.2009.12.018.

[26] Vázquez, J. A. R. 2012. A Computational Fluid Dynamics Investigation of Turbulent Swirling Burners. Ph.D Thesis. University of Zaragoza, Spain. 